\title{
Recent advances in imaging and understanding interstitial
}

\section{cystitis [version 1; peer review: 2 approved]}

\section{Pradeep Tyagi ${ }^{1}$, Chan-Hong Moon ${ }^{2}$, Joseph Janicki ${ }^{3}$, Jonathan Kaufman³, Michael Chancellor ${ }^{4}$, Naoki Yoshimura1 ${ }^{1}$, Christopher Chermansky ${ }^{1}$}

\author{
${ }^{1}$ Urology, University of Pittsburgh Medical Center, Pittsburgh, Pennsylvania, 15213, USA \\ ${ }^{2}$ Radiology, University of Pittsburgh Medical Center, Pittsburgh, Pennsylvania, 15213, USA \\ ${ }^{3}$ Lipella, Pittsburgh, USA \\ 4Urology, OU- Beaumont school of medicine, Royal oak, USA
}

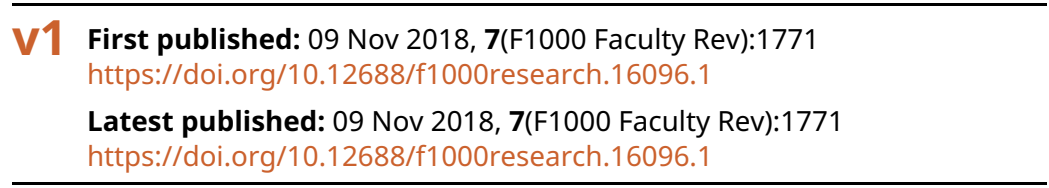

\section{Abstract}

Interstitial cystitis/bladder pain syndrome (IC/BPS) is a debilitating condition associated with intense pelvic pain and bladder storage symptoms. Since diagnosis is difficult, prevalence estimates vary with the methodology used. There is also a lack of proven imaging tools and biomarkers to assist in differentiation of IC/BPS from other urinary disorders (overactive bladder, vulvodynia, endometriosis, and prostatitis). Current uncertainty regarding the etiology and pathology of IC/BPS ultimately impacts its timely and successful treatment, as well as hampers future drug development. This review will cover recent developments in imaging methods, such as magnetic resonance imaging, that advance the understanding of IC/BPS and guide drug development.

\section{Keywords}

Interstitial cystitis, bladder wall, imaging, MRI, radiation, fibrosis

\section{Open Peer Review \\ Approval Status \\ 1 \\ 2 \\ version 1 \\ 09 Nov 2018 \\ Faculty Reviews are review articles written by the prestigious Members of Faculty Opinions. The articles are commissioned and peer reviewed before publication to ensure that the final, published version is comprehensive and accessible. The reviewers who approved the final version are listed with their names and affiliations.}

1. Longkun Li, Second Affiliated Hospital, Third Military Medical University, Chongqing, China

2. Myung-Soo Choo, University of Ulsan College of Medicine, Seoul, South Korea

Any comments on the article can be found at the end of the article. 
Corresponding author: Pradeep Tyagi (tyagip@upmc.edu)

Author roles: Tyagi P: Conceptualization, Data Curation, Formal Analysis, Funding Acquisition, Investigation, Methodology, Project Administration, Resources, Software, Supervision, Validation, Visualization, Writing - Original Draft Preparation, Writing - Review \& Editing; Moon CH: Methodology, Resources, Supervision, Validation, Visualization; Janicki J: Data Curation, Formal Analysis, Investigation, Software, Validation, Visualization; Kaufman J: Conceptualization, Funding Acquisition, Methodology, Project Administration, Resources; Chancellor M: Conceptualization, Project Administration, Resources; Yoshimura N: Investigation, Project Administration, Resources, Supervision; Chermansky C: Formal Analysis, Investigation, Methodology, Resources

Competing interests: Joseph Janicki is an employee of Lipella Pharmaceuticals, whereas Jonathan Kaufman and Michael Chancellor are inventors of novel contrast mixture. Pradeep Tyagi, Chan-Hong Moon, Naoki Yoshimura and Christopher Chermansky declare that they have no competing interests.

Grant information: This work was partly supported by National Institute of Diabetes and Digestive and Kidney Diseases grant 1R41DK108397.

The funders had no role in study design, data collection and analysis, decision to publish, or preparation of the manuscript.

Copyright: @ 2018 Tyagi $P$ et al. This is an open access article distributed under the terms of the Creative Commons Attribution License, which permits unrestricted use, distribution, and reproduction in any medium, provided the original work is properly cited.

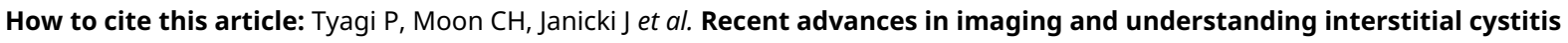
[version 1; peer review: 2 approved] F1000Research 2018, 7(F1000 Faculty Rev):1771 https://doi.org/10.12688/f1000research.16096.1

First published: 09 Nov 2018, 7(F1000 Faculty Rev):1771 https://doi.org/10.12688/f1000research.16096.1 


\section{Introduction}

Interstitial cystitis/bladder pain syndrome (IC/BPS) is a debilitating pelvic pain condition associated with bladder storage symptoms. The International Continence Society (ICS) and the European Society for the Study of IC/BPS (ESSIC) define IC/BPS as a condition with chronic ( $>6$ months) pelvic pain, pressure, or discomfort perceived to be related to the urinary bladder accompanied by at least one other urinary symptom like persistent urge to void or frequency with or without cystoscopic abnormalities. These hard-to-treat subjective symptoms often overlap with a host of other urinary disorders including urinary tract infection (UTI) ${ }^{1}$, chronic urethral syndrome, overactive bladder, hypersensitive bladder, vulvodynia, endometriosis in women, and prostatitis in men. The RAND Interstitial Cystitis Epidemiology survey estimated that 3 to 8 million women and 1 to 4 million men in the United States may have symptoms consistent with the diagnosis of IC/BPS ${ }^{2}$.

The variability of definitions (ICS, American Urological Association, ESSIC) and the abundance of non-specific symptoms and comorbidities complicate the diagnosis and management of IC/BPS ${ }^{3-5}$. Currently, the diagnosis of IC/BPS is typically based on the physician's subjective assessment and exclusion of other conditions with overlapping symptoms ${ }^{6}$, including UTI. Nevertheless, two distinct patient groups can be identified corresponding to patients with organic disease of the bladder wall ${ }^{7-9}$ and patients with painful hypersensitivity ${ }^{10}$, experiencing pain in the pelvic floor as well as other organs ${ }^{11,12}$. The ICS also recently updated the IC/BPS definition and proposed three distinct entities: pelvic hypersensitivity, IC/BPS, and IC/BPS with Hunner's lesions?2. But no objective criteria are available to differentiate patients with IC/BPS into separate entities as outlined by the updated ICS' definition.

Current uncertainty regarding the etiology and pathology of IC/ BPS ultimately impacts its treatment and hampers future drug development. Similar situations in other organs, where a disease exhibit overlapping symptoms, have been elucidated by applying imaging methods and biomarkers. Following sections will cover the current understanding of the pathophysiology of IC/BPS and the potential of different imaging techniques, particularly magnetic resonance imaging (MRI) of the bladder, pelvic floor muscles, and brain, in advancing the understanding of IC/BPS.

\section{Current understanding of the pathology}

Interstitial cystitis/bladder pain syndrome originating from the bladder

IC/BPS patients of this category ${ }^{8,9}$ are considered to have an organic disease of the bladder wall. Pathological examination of biopsy specimens from the bladder wall of such IC/BPS patients typically finds a higher incidence of mucosal hemorrhages (glomerulations), submucosal inflammation ${ }^{13}$ and a high density of mast cells ${ }^{14,15}$, which is associated with hyperexcitability ${ }^{16}$ of afferent nerve fibers ${ }^{17}$. Cystoscopic detection of glomerulations in the bladder mucosa of IC/BPS patients is the defining characteristic of the ESSIC type $2 \mathrm{C}$ classification, while the detection of Hunner's lesion (a denudation of urothelium) is a sign of classic type or ESSIC type 3C, more commonly referred to as Hunner-type IC/BPS. Hunner-type IC/BPS is seen in $5-10 \%$ of cases and the analysis of their bladder wall biopsy is generally associated with high expression of $\mathrm{T}$ and $\mathrm{B}$ cell markers ${ }^{18}$, low expression of urothelial markers, high density of mast cells, focal lymphoid aggregates, overexpression of IL-6, IL-10, IL-17A, and inducible NOS (iNOS) mRNA $^{14}$. Analysis of urine specimens found higher concentration of immunoglobulin and inflammatory mediators. Our current understanding is that most IC/BPS patients in the population do not present with Hunner's lesions and therefore are classed as having non-Hunner-type IC/BPS ${ }^{19}$. To date, bladder wall biopsy is the only available method to detect mast cells ${ }^{20}$ and molecular signatures of chronic inflammation in the bladder wall, but the method is limited by invasiveness and potential complications. Different fixation/staining techniques for mast cells ${ }^{21}$ also add to the confusion. Therefore, there is a need for a non-invasive imaging method to identify patients with organic disease of the bladder wall.

\section{Contribution of bladder permeability and interstitial cystitis/ bladder pain syndrome}

Multiple lines of evidence now support a role for increased bladder permeability in IC/BPS patients with organic disease of the bladder wall ${ }^{22-24}$. Denudation of the glycosaminoglycan (GAG) layer located at the luminal surface of the bladder ${ }^{24,25}$ by protamine sulfate leads to increased bladder permeability, which can be ameliorated by long-term oral or intravesical administration of GAG substitutes. Past published studies used the serum uptake of intravesically instilled urea ${ }^{24}$ or radionuclide ${ }^{26}$ as an index of bladder permeability. However, serum uptake ${ }^{26}$ of instilled substances is subject to considerable inter-individual variability in the distended bladder wall thickness ${ }^{27}$ and the volume of systemic distribution. Large divergence in the published findings ${ }^{24,26}$ can easily be explained by the differences in the molecular weight (60 versus $487 \mathrm{Da})$ of urea and the radionuclide used as a probe.

The contribution of bladder permeability to the pathophysiology of IC/BPS is also supported by the immunohistochemical and ultrastructural studies of biopsies taken from IC/BPS patients. Decreased expression of tight junction protein and adhesive junction proteins including E-cadherin and zonula occludens-1 (ZO-1) as well as the differentiation marker uroplakin ${ }^{22,28}$ supports the role of bladder permeability in IC/BPS pathogenesis. Electron microscopy of the urothelium in the biopsies revealed the contribution of leaky tight junctions in IC/BPS ${ }^{23}$. Umbrella cells are pleomorphic in the apical layer of the urothelium, and a decrease in the microplicae (ridges) in umbrella cell membranes was suggested to be pathognomonic for IC/BPS ${ }^{29}$. Furthermore, upregulation of the purinoceptor P2X3 and an increased release of adenosine triphosphate from the urothelium is also reported in IC/BPS patients ${ }^{30}$. However, biopsy-based studies are sensitive to site selection, which can lead to the apparent variability in the morphological differences between the urothelium of IC/BPS patients and controls ${ }^{29,31,32}$.

\section{Contribution of fibrosis in interstitial cystitis/bladder pain syndrome}

Fibrosis, or tissue scarring, often results from the evolutionarily conserved process of wound healing to resolve chronic inflammation. Progressive fibrotic changes in the bladder wall of IC/BPS 
patients are characterized by excessive deposition of extracellular matrix within the lamina propria and smooth muscle (Figure 1), generation of contractile fibroblasts (myofibroblasts), and decreased capillary density ${ }^{33,34}$. These histological changes are associated with the upregulation of collagen genes, collagen I, collagen III, fibronectin, and transforming growth factor- $\beta 1$ (TGF- $\beta 1)^{35}$ and the downregulation of sonic hedgehog, WNT gene family, WNT2B, WNT5A, WNT10A, and WNT11 in the biopsy of non-Hunner-type IC/BPS patients ${ }^{33,36-40}$. Recent studies report the association of YKL-40 antigenic expression in detrusor mast cell granules and submucosal macrophages with detrusor fibrosis $^{34}$ and the activation of mammalian target of rapamycin (mTOR) with fibrosis in ketamine-induced ${ }^{41}$ IC/BPS.

Changes in collagen gene expression in biopsy specimens representing the mucosa and submucosa tissue layers of the bladder wall are consistent with the increased collagen staining in the intra- and inter-fascicular muscle tissue of IC/BPS patients ${ }^{15}$. Histological detection of fibrosis in the bladder wall is associated with increased passive tissue stiffness during stretch, reduced bladder compliance ${ }^{42}$, uninhibited detrusor contractions ${ }^{43}$, higher urinary frequency, and lower bladder capacity ${ }^{43}$. However, decreased bladder capacity ${ }^{7}$ is not a specific marker for IC/BPS patients, as both IC/BPS and overactive bladder patients ${ }^{44}$ exhibit decreased bladder capacity. Fibrotic changes in non-Hunner-type IC and Hunner-type IC IC $^{15,33,34,45}$ are significantly associated with the failure of standard treatment and the need for aggressive treatment options of steroids or hydrodistension with deep bladder biopsies, pain clinic, or surgery (e.g. urinary diversion and cystectomy) in extreme cases. Therefore, earlier detection of fibrotic changes can guide the pre-emptive addition of anti-fibrotic therapy for improved treatment outcomes.

\section{Imaging techniques}

Average thickness of human bladder wall is approximately $3 \mathrm{~mm}$, composed of detrusor smooth muscle sandwiched between the mucosa and the adventitia ${ }^{46}$, which makes it challenging to image by available planar and tomographic imaging techniques.

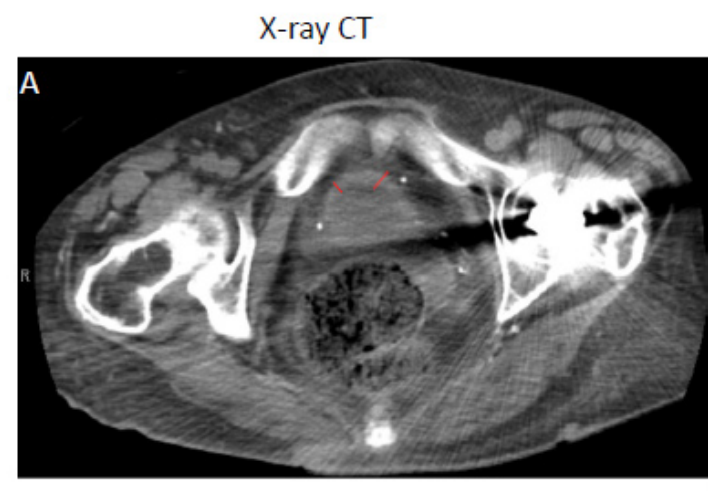

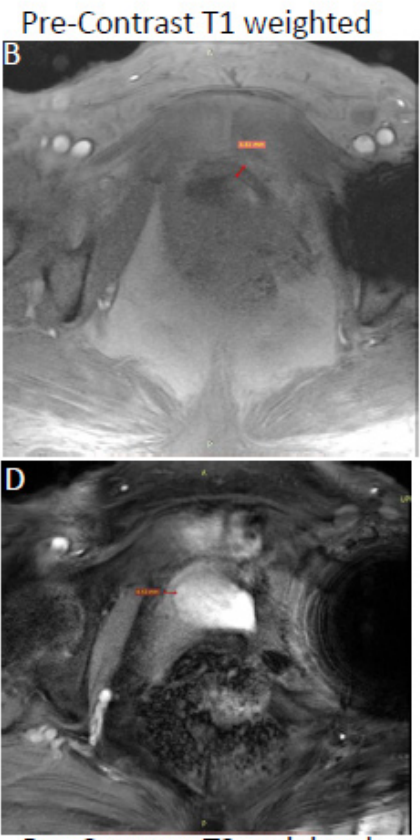

Pre-Contrast T2 weighted
Post-Contrast T1 weighted

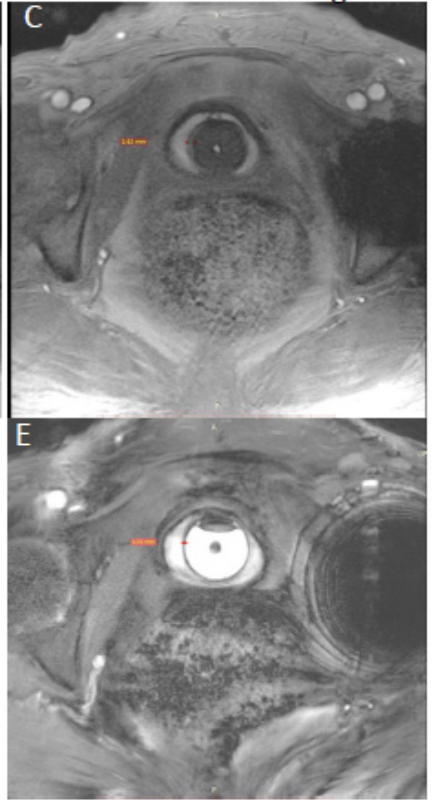

Post-Contrast T2 weighted

Figure 1. Magnetic resonance imaging (MRI) is superior to computed tomography (CT) in bladder wall segmentation. Contrastenhanced $T_{1}$-weighted MRI (Panel C) is superior to CT (Panel A) and unenhanced $T_{1}$-weighted MRI (Panel B) for resolving the thickened bladder wall of the same female ulcerative interstitial cystitis/bladder pain syndrome (IC/BPS) patient as indicated by a red line drawn across the bladder wall. Representative $\mathrm{T}_{1}$-weighted fast low angle shot (FLASH) images acquired at the flip angle of $14^{\circ}$ in orthogonal orientation before (Panel $\mathbf{B}$ ) and after novel contrast mixture (NCM) instillation (Panel $\mathbf{C}$ ) demonstrate that NCM-enhanced MRI can noninvasively segment the bladder wall into a middle layer of bright signal intensity sandwiched between inner and outer layers of lower signal intensity. Fibrotic changes reported in the pathological results of the biopsy from the IC/BPS patient are visible as the bright middle layer from the diffusion of gadobutrol from NCM instilled in the lumen (hypointense circular region in Panel C). Fast acquisition of a single slice ( $5 \mathrm{~mm}$ thickness) over a single breath hold of approximately 17 seconds with imaging parameters of repetition time (TR)/echo time (TE) of $5.5 / 2$ milliseconds, field of view of $180 \times 180 \mathrm{~mm}^{2}$, matrix of $256 \times 256$ and 10 averaging achieved in-plane resolution of $0.35 \mathrm{~mm}$ (after $2 \times$ interpolation) with minimal influence of motion and chemical shift artifacts (Panel B and C). Akin to CT (Panel A), $\mathrm{T}_{1}-$ weighted MRI (Panel B) with similar imaging parameters as in Panel $\mathbf{C}$ could not resolve the bladder wall from the lumen in the absence of NCM owing to the relatively long intrinsic $T_{1}$ relaxation time of $>1$ second for the bladder wall and of urine in the lumen. Although the bladder wall is demarcated clearly in pre-contrast $T_{2}$-weighted image (Panel $\mathbf{D}$ and $\mathbf{E}$ ) acquired at the TR/TE of 6.9/3.1 milliseconds, there is underestimation of bladder wall thickness, especially of the inner layer from $3.62 \mathrm{~mm}$ in panel C to $1.21 \mathrm{~mm}$ in Panel E. Instillation of gadobutrol (GBCA) in the absence of ferumoxytol enhances the $T$, contrast of urine as well as the bladder wall, which precludes it from affording improved image contrast. This figure is an original image taken in our clinic for this publication. 


\section{Planar imaging techniques}

Cystoscopy. Cystoscopy is a planar imaging technique with a small field of view (FOV) for direct, real-time image guidance of the bladder wall. The ICS regards cystoscopy as the standard technique to identify IC/BPS patients with Hunner's lesions ${ }^{47}$. Two-dimensional (2D) images generated via cystoscope show Hunner's lesions on the luminal surface of bladder wall as either singular or multiple erythematous mucosal patches, with small vessels radiating toward a discrete central pale scar with fibrin or coagulum. Fissure and glomerulations (petechial hemorrhages) are visible during bladder emptying after hydrodistention with cascade bleeding. The absence of Hunner's lesions on cystoscopic examination classifies the patients as non-Hunner-type IC/BPS. The detection of Hunner's lesions can guide appropriate surgical treatment of the lesion including transurethral cauterization or fulguration and consideration of hydrodistension under general anesthesia in the absence of Hunner's lesions ${ }^{48}$. However, small FOV of cystoscopy limits its sampling to small tissue volumes, and it can easily miss bladder wall changes that are morphologically indistinct from normal bladder wall ${ }^{49}$. Moreover, this gross morphological discrimination is unable to exclude patients with an abnormality in their pelvic floor.

Ultrasound. Available ultrasound techniques to image the bladder wall produce widely variable outcomes depending on the anatomical approach (translabial/transperineal and suprapubic), frequency, and other factors ${ }^{46}$. Detrusor smooth muscle is hypoechogenic (dark), whereas the mucosa and the outer layer of the adventitia are hyperechogenic (bright). Since bladder wall and detrusor become thinner as the bladder fills, values of the bladder wall thickness (BWT) drop by about $1 \mathrm{~mm}$ for each increase in bladder volume distension by $50 \mathrm{~mL}$. Therefore, most measurements of BWT in the range of $3 \mathrm{~mm}$ to $6.5 \mathrm{~mm}$ are made with bladder filling volume of less than $50 \mathrm{~mL}$ using a 5-9 $\mathrm{MHz}$ probe. Since image resolution with ultrasound is only limited to $1 \mathrm{~mm}$, a distended bladder wall may only be represented by around 3 image pixels. Ultrasound is generally used to detect renal involvement, pelvic floor muscle mobility ${ }^{50}$, and thickening of the bladder wall in recurrent $\mathrm{UTI}^{51,52}$ and in IC/BPS ${ }^{53}$ patients.

Near-infrared imaging. The application of conventional fluorescent microscopy for imaging the bladder wall is limited owing to the issues pertaining to absorption by tissues, scattering, and auto-fluorescence of visible light ${ }^{54}$. Recently, fluorochromes emitting in the near-infrared (NIR) band were shown to emit light with tissue penetration approaching $10-15 \mathrm{~cm}^{55}$. Low background auto-fluorescence and minimal absorption by tissue components $^{54}$ in the NIR band make it suitable for deeptissue imaging ${ }^{56}$ (Figure 2). In a rodent study, the instillation of liposomes containing NIR dye allowed visualization of the instilled liposomes in anaesthetized mouse bladder wall ${ }^{57}$. NIR spectroscopy (NIRS) is a non-invasive, functional, transcutaneous optical technique that uses NIR light to monitor changes in the concentration of oxyhemoglobin and deoxyhemoglobin in the bladder wall. Thus, optical monitoring of bladder wall oxygenation is feasible with $\mathrm{NIRS}^{58}$ to potentially delineate the contribution of ischemia to IC/BPS symptoms.
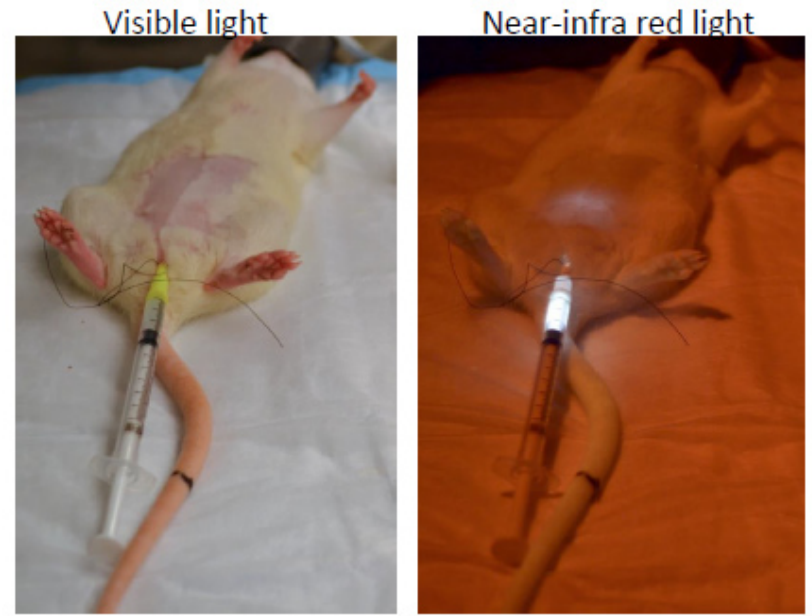

Figure 2. Near infra-red imaging. Representative images for the rat pelvic area in visible light and in near infra-red (NIR) light after instillation of liposomes containing a trace amount of NIR dye. Deep tissue imaging of the bladder wall is possible, as light emitted from the bladder lumen in the NIR band encounters low background autofluorescence and minimal absorption by tissue components. This figure is an original image taken in our clinic for this publication.

\section{Tomographic imaging techniques}

Tomographic imaging techniques are capable of threedimensional (3D) display and acquisition of multiple slices across multiple planes. Such a large image volume is enormously rich in potential information, but the complex instrumentation and intensive image analysis preclude real-time feedback. The potential of tomographic image visualization and quantitative analysis in the diagnosis and treatment of IC/BPS remains unrealized.

X-ray computed tomography. Abdominal computed tomography (CT) is a tomographic imaging technique which was recently used to detect the treatment-associated decrease in bladder wall thickening of IC/BPS patients ${ }^{59}$, identify hidden lesions under scanned area, and exclude malignancies. However, CT exposes patients to high doses of ionizing radiation (X-ray) and lacks the sensitivity to detect the onset and progression of fibrosis. Figure 1 illustrates the relative contrast resolution (degree of difference between brightest and darkest component of an image) of the bladder wall with CT and MRI.

Magnetic resonance imaging. MRI is a safe imaging technique that does not rely on ionizing radiation for tomographic imaging of visceral organs. MRI affords higher contrast and spatial resolution of soft tissue in multiplanar images ${ }^{60}$, which makes it one of the preferred imaging modalities in urology. MRI is especially superior to $\mathrm{CT}$ in reliably producing slices more suited to detect lesions in the dome and base of the bladder wall. MRI also allows diffusion imaging and dynamic contrast enhancement in the bladder wall ${ }^{60}$. However, there is no reference signal for MRI corresponding to the standard reference signal of 0 Hounsfield units for the radio density of water in CT. So, MR image quality in terms of both image contrast (Figure 1) 
and spatial resolution is described by contrast resolution or contrast-detail measured by contrast-noise ratio $(\mathrm{CNR})^{61}$.

\section{Conventional MRI}

Exquisite soft tissue contrast in conventional $\mathrm{T}_{1}$ - and $\mathrm{T}_{2}$-weighted MRI arises principally from the differences in the intrinsic tissue relaxation times $T_{1}$ (spin-lattice relaxation time) ${ }^{62}$ and $T_{2}$ (spin-spin relaxation time) ${ }^{10,63,64}$. Variation in signal sensitivity (rise in CNR) to highlight the differences in $\mathrm{T}_{1}{ }^{62}$ and $\mathrm{T}_{2}{ }^{63,64}$ for $\mathrm{T}_{1}$ weighted and $\mathrm{T}_{2}$-weighted images ${ }^{63,65}$ is commonly achieved by manipulating the acquisition parameters (e.g. flip angle [FA], echo time [TE], repetition time [TR], inversion time, etc.). Unenhanced $\mathrm{T}_{1}$-weighted MRI requires a TR of $>4-5$ times the $\mathrm{T}_{1}$ relaxation time of the target organ. Hence, a relatively long intrinsic $T_{1}$ relaxation time of $>1$ second for bladder wall and of $>6$ seconds for urine at magnetic field strength of 3 Tesla $(\mathrm{T})^{62,66}$ requires a TR of $>5$ seconds, which prolongs the image acquisition ( $>5$ minutes) $)^{67}$ and the resulting image quality of the thin human bladder wall ${ }^{68,69}$ becomes highly susceptible to artifacts from involuntary bowel and respiratory motion of the subject ${ }^{70}$. Moreover, multiple signal averages ${ }^{63}$ with prolonged image acquisition for $\mathrm{T}_{1}$-weighted MRI of the bladder wall can only achieve in-plane resolution of $>0.5 \mathrm{~mm}^{71,72}$.

We recently showed that the use of a short TR of 5.5 milliseconds increases the image resolution in $\mathrm{T}_{1}$-weighted MRI (Figure 1B), but the isointense signal in the bladder wall and urine $^{62}$ makes it difficult to differentiate the thin human bladder wall from the urine. Though the human bladder wall is more distinguishable in $\mathrm{T}_{2}$-weighted MRI (Figure 1D) (33,73 $^{6} \mathrm{~T}_{1}$-weighted $\mathrm{MRI}^{67}$ is preferable for its higher signal-to-noise ratio (SNR) and accurate measurement of BWT $^{69,73-75}$ for characterizing bladder disorders ${ }^{51}$. As shown in Figure 1, the thickness of the inner layer (urothelium) of the bladder wall is underestimated in $\mathrm{T}_{2}$ weighted images ${ }^{75,76}$. The bladder wall appears as a thin layer of intermediate intensity on $\mathrm{T}_{2}$-weighted images and is likely to correspond to the thickness indicated by the middle and outer layer on the contrast-enhanced $\mathrm{T}_{1}$-weighted image (Figure 1C) ${ }^{65}$. It appears that the highly intense signal of urine in unenhanced $\mathrm{T}_{2}$-weighted images submerges the signal from a portion of the urothelium layer, leading to BWT underestimation ${ }^{75}$. Since lesions in the bladder wall associated with IC/BPS are generally restricted to the urothelium, $\mathrm{T}_{2}$-weighted MRI can easily miss the important details for pathological characterization of IC/BPS. $\mathrm{T}_{2}$-weighted MRI is also not suitable for staging the bladder cancer before invasion of muscular layer ${ }^{65}$.

Furthermore, the sandwich composition of the bladder wall's histology can displace the respective MR signals in the readout direction to produce chemical shift mis-registration of the perivesical fat signal and exaggerate motion $\operatorname{artifacts}^{66,77,78}$. Chemical shift artifact refers to the signal alterations that result from the $440 \mathrm{~Hz}$ difference in the resonant frequencies of fat and water protons at $3 \mathrm{~T}^{66,78}$. Therefore, variable shape, location, and histological composition of the bladder wall limits the utility of conventional MRI in the diagnosis and treatment of IC/BPS. Nevertheless, urinary bladder can be visualized by MRI in multiple cross-sectional orientations with parallel image series in cross-sectional imaging planes and intersectional at different orientations. However, the information in 2D image slices is non-continuous owing to slice gaps. Hence, improvements in bladder wall imaging call for enhancement of contrast, SNR and reduced susceptibility to artifacts $^{79}$ during image acquisition and $3 \mathrm{D}$ reconstruction.

\section{Contrast-enhanced MRI}

One of the traditional approaches to enhance $T_{1}$ contrast of the human bladder wall is the intravenous injection of gadoliniumbased contrast agents (GBCAs). Entry of blood containing the injected GBCAs into the middle layer of the bladder wall can briefly differentiate it into three layers: a thin inner layer of low intensity, a middle layer of strong intensity, and a thick outer layer of intermediate intensity in post-contrast images ${ }^{65}$. However, subsequent entry of the GBCA excreted into urine within 3 minutes of injection ${ }^{80,81}$, and continuous accumulation of urine in bladder ultimately reduces the contrast between the lumen and bladder wall ${ }^{69,73,82}$. Moreover, the $T_{2}$ relaxation effect of $\mathrm{GBCAs}^{80,83}$ causes pseudolayering in the urine collected in the lumen ${ }^{73}$. To overcome the drawbacks associated with the intravenous administration of GBCAs, several groups have now tried intravesical administration of GBCAs in bladder cancer ${ }^{84}$, vesicoureteral reflux ${ }^{85}$, and IC/BPS ${ }^{86}$. But the enhancement of $\mathrm{T}_{1}$ contrast in the urine by the instilled GBCA analog gadolinium-diethylenetriaminepentaacetic acid prevents it from offering a good image contrast in the bladder wall ${ }^{69,84,86}$ and accurately measuring the BWT. Likewise, instillation of superparamagnetic iron oxide (SPIO) nanoparticles ${ }^{87}$ has also been tried without much success to improve the contrast of the human bladder wall ${ }^{88}$.

Our group recently reported that novel contrast mixture (NCM) can improve the image contrast of the bladder wall in $\mathrm{T}_{1}$-weighted MRI of $\operatorname{rat}^{88}$ and human bladder ${ }^{61}$ (Figure 1C, Figure 3, and Figure 4). NCM is a homogenous mixture of gadobutrol (GBCA) diluted 1:250 and ferumoxytol (SPIO) diluted 1:104 in sterile water for irrigation (Panel A). Gadobutrol (transparent liquid) with a molecular weight of $604.71 \mathrm{Da}$, whether injected intravenously or instilled into bladder, reaches the extracellular space in the lamina propria to produce $\mathrm{T}_{1}$ contrast (signal increase). Meanwhile, the large molecular weight of 750 $\mathrm{kDa}$ restricts the bladder wall diffusion of ferumoxytol (vial with brown-colored liquid) to primarily exert $T_{2}$ contrast (signal decrease) in the lumen and produce a localized increase in proton dephasing of $\mathrm{T}_{1}$-weighted FLASH (fast low angle shot) MRI at a TR/TE of 5.5/2 milliseconds. $\mathrm{T}_{1}$-weighted FLASH images of the tubes containing gadobutrol or NCM in Figure 4 A-B illustrate that the presence of ferumoxytol $(5 \mathrm{mM})$ in the NCM tube masks the gadobutrol-mediated signal enhancement, which is visible with an increase in FA from $6^{\circ}$ (panel A) to $14^{\circ}$ (panel B) in the right tube containing gadobutrol $4 \mathrm{mM}$ alone. The concentration of gadobutrol $(4 \mathrm{mM})$ is the same in both tubes identified as NCM and gadobutrol. Likewise, the separation of gadobutrol away from NCM instilled in the lumen dramatically increases the signal intensity in the bladder wall of ulcerative IC/BPS patients (Figure 4E-F) but not in the non-ulcerative IC/BPS patient (Figure 4C-D), which indicates that a greater physical 


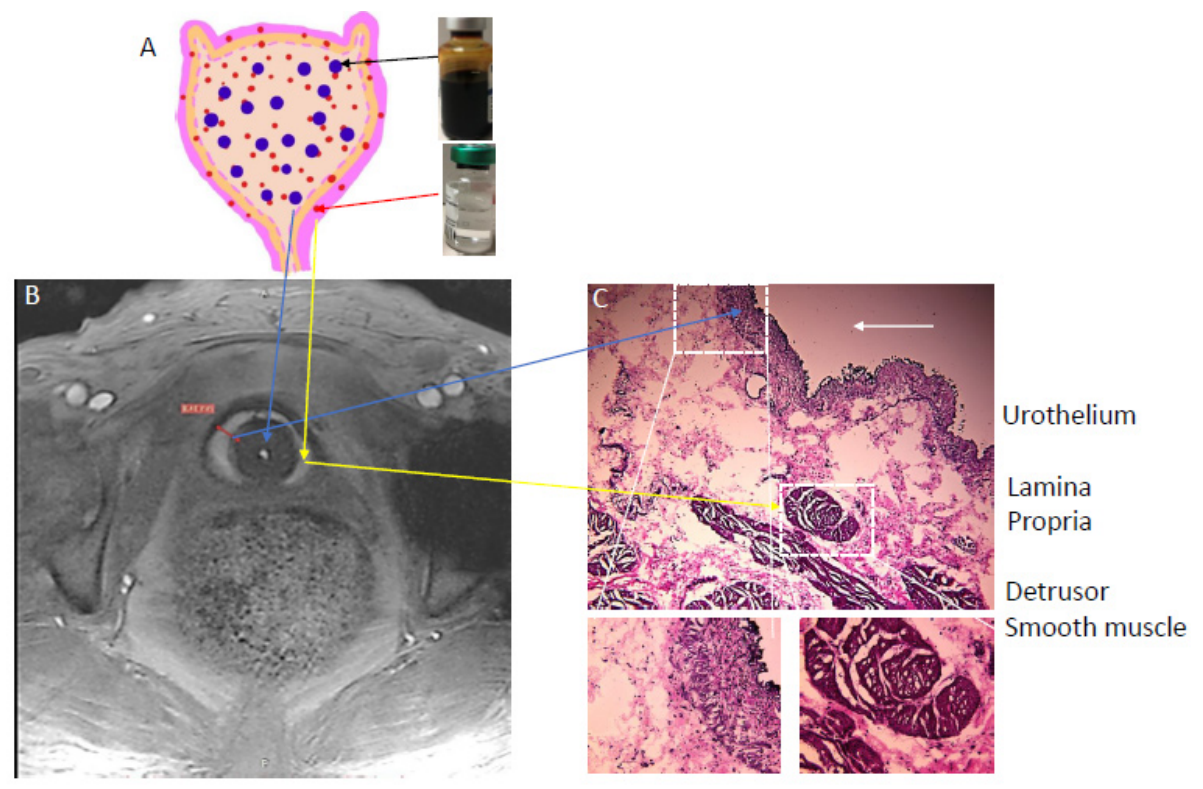

Figure 3. Contrast-enhanced magnetic resonance imaging (MRI) relies on the diffusion of gadolinium into the bladder wall. Novel contrast mixture-enhanced MRI relies on the differences in the contrast mechanisms and molecular weight of two US Food and Drug Administration-approved agents (gadobutrol diluted 1:250 and ferumoxytol diluted 1:104) for increasing the contrast resolution of the bladder wall (Panel A). Gadobutrol, a transparent liquid, is a gadolinium-based contrast agent (GBCA) with a molecular weight of 604.71 Da that reaches the extracellular space in the lamina propria to shorten $T_{1}$ (positive contrast) or produce higher signal intensity (Panel $\mathbf{A}$ and $\mathbf{B}$ ). Meanwhile, the large molecular weight of $750 \mathrm{kDa}$ for ferumoxytol (vial with brown-colored liquid) restricts its bladder wall diffusion, and it produces a localized increase in proton dephasing, which decreases the signal intensity (negative contrast) in $\mathrm{T}_{1}$-weighted images. Instillation of novel contrast mixture $50 \mathrm{~mL}$ can non-invasively segment the inner layer (urothelium) and the outer layer of adventitia (dark signal) from the bright signal in the middle layer composed of the lamina propria and detrusor smooth muscle (Panel C). Bladder wall histology in Panel C is shown for illustration and does not represent the pathological characterization of the interstitial cystitis/bladder pain syndrome (IC/BPS) patient shown in Panel B. This figure is an original image taken in our clinic for this publication.

separation of gadobutrol from ferumoxytol occurs from the diffusion of gadobutrol into the bladder wall away from the NCM instilled in the bladder lumen of ulcerative IC/BPS patients.

Post-contrast images of human bladder wall were acquired after $50 \mathrm{~mL} \mathrm{NCM}$ instillation to achieve artifact-free visualization of the bladder wall with an in-plane resolution of $<0.5 \mathrm{~mm}$. The use of a short TR of 5.5 milliseconds with 10 averages shortened the image acquisition from 5 minutes to a single breath hold of 17 seconds and reduced the susceptibility to motion artifacts. A higher number of pixels representing the bladder wall and high readout bandwidth of $574 \mathrm{~Hz} /$ pixel ensure that the mis-mapping of the water and fat signals is limited to a pixel (i.e. 0.7 pixels $=440 \mathrm{~Hz} / 574 \mathrm{~Hz})^{66,78}$. Contrast-enhanced MRI (CE-MRI) of the ulcerative IC/BPS patient after the instillation of NCM revealed segmentation into three layers of different signal intensity in post-contrast images taken at the FA of $14^{\circ}$, where the middle layer of bright signal intensity was sandwiched between the inner and outer layers of lower signal intensity. The constant TR of 5.5 milliseconds at different FAs achieves the stable steady-state conditions necessary for the signal intensity measurement of the same slice at different FA to become a function of the $\mathrm{T}_{1}$ relaxation time (Figure $4 \mathrm{G}$ and $4 \mathrm{H}$ ).

In a study published by another group, GBCA was instilled at the rate of $2-2.5 \mathrm{cc}$ per second over a 5-10 minute period or a total volume of $600-800 \mathrm{~mL}^{86}$. In comparison, a standard volume of $50 \mathrm{~mL}$ for $\mathrm{NCM}$ instillation is likely to be more tolerable for a subset of severe IC/BPS patients with low bladder capacity of $200-400 \mathrm{~mL}^{7,89}$. Bladder wall thinning of approximately $0.41 \mathrm{~mm}$ measured after $50 \mathrm{~mL}$ instillation for NCM-enhanced $\mathrm{T}_{1}$-weighted $\mathrm{MRI}^{61}$ is consistent with the ultrasound measurements of BWT distended to similar volumes ${ }^{46}$. It is known that overdistention of the bladder wall can provoke motion artifacts in sensitive patients and the consequent thinning of the bladder wall can also hinder the differentiation of tissue layers and the luminal texture ${ }^{90}$.

Pelvic magnetic resonance imaging as a tool to assess the contribution of bladder permeability in interstitial cystitis/bladder pain syndrome

Instead of serum uptake, $\mathrm{T}_{1}$-weighted CE-MRI in IC/BPS patients relies on the penetration of an instilled GBCA into the bladder wall as a non-invasive measure of bladder permeability ${ }^{86,91,92}$. Towner et al. reported that instillation of GBCA bestowed greater skewness and kurtosis in the probability distribution for the bladder wall signal intensity ${ }^{86}$. It is worth stating here that the signal intensity measurement in MRI depends on several factors, including intrinsic properties of the tissue and the acquisition parameters, receiver coil geometry, sensitivity, and signal amplifier gains. These variables introduce a non-linearity into the signal intensity measurement and differences in 


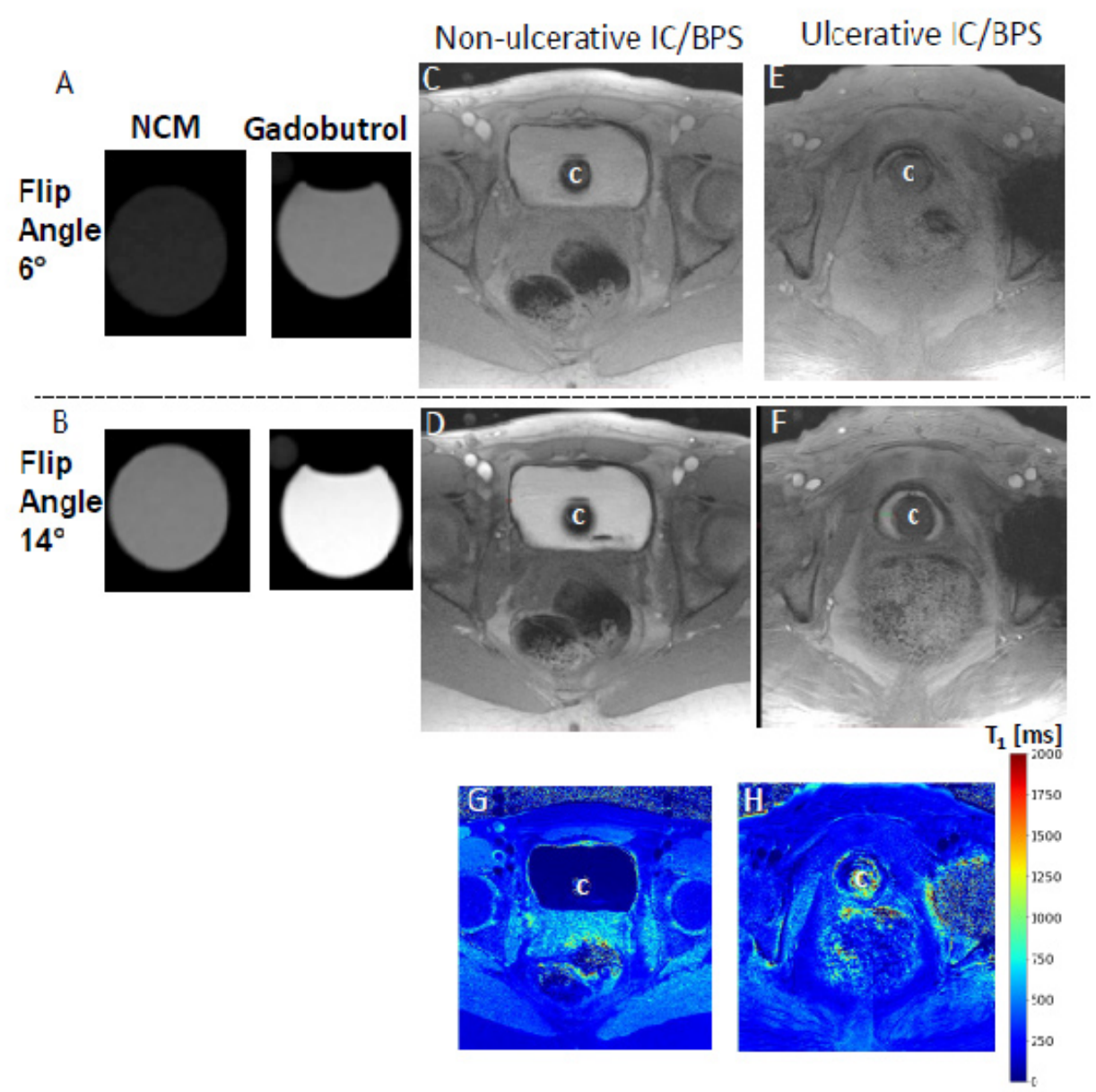

Figure 4. Quantitative measurement of gadolinium diffusion. $T_{1}$-weighted fast low angle shot (FLASH) images with constant repetition time (TR) of 5.5 milliseconds (ms) at flip angle (FA) of $6^{\circ}$ (Panel A, C, and E) and $14^{\circ}$ (Panel B, D, and E) demonstrate that gadobutrol-mediated signal enhancement (visible in the right tube containing gadobutrol $4 \mathrm{mM}$ alone) is suppressed by the presence of ferumoxytol (5 mM) in the novel contrast mixture (NCM) tube, as the gadobutrol concentration of $4 \mathrm{mM}$ is the same in both tubes (Panel $\mathbf{A}$ and $\mathbf{B}$ ). $\mathrm{T}_{1}$-weighted FLASH images demonstrates that greater separation of gadobutrol into the bladder wall away from the NCM instilled in the bladder lumen occurs in ulcerative IC/BPS patients (Panel E and $\mathbf{F}$ ) than in non-ulcerative interstitial cystitis/bladder pain syndrome (IC/BPS) patient (Panel $\mathbf{C}$ and D), which is evident from the dramatic increase in signal intensity in Panel $\mathbf{F}$ relative to Panel $\mathbf{D}$ at FA of $14^{\circ}$. Catheter used for instillation is shown by $\mathbf{C}$ in panel $\mathbf{C}-\mathbf{H}$. Constant TR of $5.5 \mathrm{~ms}$ at different FAs achieves the stable steady-state conditions necessary for the differences in signal intensity of the same slice to become a function of $\mathrm{T}_{1}$ relaxation time as indicated by the color panel in Panel $\mathbf{H}$. Greater shortening of $\mathrm{T}_{1}$ relaxation time (blue color) in ulcerative IC/BPS patients is consistent with higher diffusion of gadobutrol into the expanded extracellular matrix of the thickened bladder wall of IC/BPS patients. This figure is an original image taken in our clinic for this publication.

hardware used at different places preclude any direct comparisons of intensity values across patients or imaging centers. Moreover, hypointense signal intensity in the inner layer of the bladder wall (Figure 1C and Figure 3) after NCM instillation indicates that quantitative measurement of the bladder wall signal intensity following GBCA instillation is especially vulnerable to the MRI artifacts ${ }^{62,66,77,78}$.

Passive diffusion of gadobutrol into the bladder wall is presumed to create a downhill concentration gradient of GBCA with the highest concentration in the innermost layer. However, signal intensity in different tissue layers of the bladder wall does not show a similar downhill gradient owing to the $\mathrm{T}_{2}$ relaxation effect of GBCA at higher concentrations ${ }^{80,83}$, which reduces the relative signal intensity of the inner layer compared to the middle layer of the bladder wall. The $T_{2}$ relaxation effect of the GBCA is also known to cause pseudolayering in urine containing excreted GBCA accumulated in the bladder after intravenous injection of the $\mathrm{GBCA}^{80}$. Also, a role for an increased proton dephasing from localized perturbation of the magnetic field by ferumoxytol cannot be ruled out in the lowering of the signal intensity in the inner layer. Since signal intensity measurement in CE-MRI can introduce errors in bladder wall permeability measurement, the interpretation of the imaging data can be simplified by direct calculation of the proton density and spin relaxation times. Hence, acquisition $T_{1}$ relaxation time can facilitate improved 
characterization of the bladder wall, enhance image tissue contrast, and provide a more direct link between the observed signal changes and pathological changes detected by bladder wall biopsy. Besides, quantitative relaxometry (quantitative measurement of $T_{1}$ relaxation time) can facilitate the standardization of bladder wall imaging for longitudinal study on the same patient and multicenter studies.

In a small pilot study of six subjects, we used the differences in signal intensity at different FAs to calculate the $T_{1}$ relaxation time, which is an intrinsic property of tissues. $T_{1}$ graphically represents the first order time constant required for the Z-component of net magnetization to reach (1-1/e) or about $63 \%$ of its maximum signal intensity ${ }^{93}$. A change in the longitudinal relaxation rate $\left(1 / \mathrm{T}_{1}\right)$ of the tissue is directly proportional to the GBCA concentration in the tissue ${ }^{94}$. However, the acquisition of artifact-free, high-resolution imaging of human bladder wall is a prerequisite for mapping the $T_{1}$ relaxation time and for deriving the bladder wall permeability data. Therefore, automatic acquisition of the pre-contrast and post-contrast pixel wise $T_{1}$ maps obtained after NCM (Figure 4G and $4 \mathrm{H}$ ) can be a robust measure of bladder wall permeability. The variable $\mathrm{FAs}^{95}$ method is a preferred alternative to the LookLocker method for quantitative measurement of bladder wall $\mathrm{T}_{1}$, as it does away with the inversion pulse and clinically infeasible times required to more fully characterize the recovery curves. The differences in signal intensity at different FAs in different layers of the bladder wall were transformed to a homogenous blue color indicating the shortening of the bladder wall $\mathrm{T}_{1}$ following diffusion of gadobutrol from instilled NCM (Figure 4).

Studies on the heart and liver have demonstrated that fibrotic changes $^{96,97}$ increase the $T_{1}$ relaxation time and therefore quantitative $T_{1}$ measurement ${ }^{98}$ of the bladder wall is proposed as an objective and reproducible parameter for the non-invasive detection of diffuse histological changes such as edema and fibrosis without resorting to bladder wall biopsy. Indeed, the bright middle layer in the bladder wall (Figure 1C, Figure 3B, and Figure 4F) is consistent with the evidence of fibrosis noted in the bladder biopsy and bladder wall thickening noted in CT of the same IC/BPS patient. Therefore, quantitative measurement of bladder wall $\mathrm{T}_{1}$ can become a non-invasive biomarker of diffuse tissue changes leading to increased bladder wall permeability, which can help the clinician to discriminate IC/BPS from other pelvic floor defects. In recent years, the use of $\mathrm{T}_{1}$ mapping techniques has been simplified and can be readily integrated into clinical MRI examination.

Pelvic magnetic resonance imaging as a tool to assess the contribution of pelvic floor hypertonicity in interstitial cystitis/ bladder pain syndrome

The anatomies of pelvic structures ${ }^{99,100}$ are critical for the diagnosis of pelvic floor hypertonicity. The contribution of pelvic floor hypertonicity to pain in 15 female IC/BPS patients and age-matched controls was investigated with $\mathrm{T}_{2}$-weighted MRI without instilling or injecting any contrast agents. Increased pelvic floor hypertonicity in IC/BPS patients was linked to shortened levator muscles, wider posterior puborectalis angle, and decreased puborectal distances. While the total urethral length and $\mathrm{M}$ line were similar in two cohorts, the $\mathrm{H}$ line was shorter and the vaginal cuff and bladder neck distances to the $\mathrm{H}$ line were longer in patients with IC/BPS. These observations need to be considered in light of the known age dependence in the displacement of the bladder and vagina ${ }^{99}$ and as-yet-unknown contribution of neuronal factors, decrease in muscle strength/mass, or fat deposition. Pelvic magnetic resonance 3D reconstructed images can reveal the anatomical relationships of pelvic organs with each other ${ }^{101}$.

Brain magnetic resonance imaging as a tool to assess the contribution of central pain processing

In a multicenter study, high-resolution $\mathrm{T}_{1}$-weighted $\mathrm{MRI}^{11}$ and functional MRI (fMRI) ${ }^{12}$ of brain was used to detect alterations in central pain processing of well-phenotyped IC/BPS patients. Compared to healthy controls, the pain, mood (anxiety), and urological symptoms of $33 \mathrm{IC} / \mathrm{BPS}$ patients were associated with a notably elevated volume of gray matter in a number of different brain regions. A separate study examined the 10-minute resting brain fMRI of 85 IC/BPS patients and 85 female healthy controls $^{12}$ to detect blood oxygen level-dependent signal, which was then transformed to the frequency domain. Altered frequency distributions in viscerosensory (post insula), somatosensory (postcentral gyrus), and motor regions (anterior paracentral lobule and medial and ventral supplementary motor areas) were detected in IC/BPS patients relative to controls. IC/BPS patients also showed increased functional connectivity of the anterior paracentral lobule and medial and ventral supplementary motor areas to the midbrain (red nucleus) and cerebellum. Patients who experienced pain during bladder filling had the highest level of increased functional connectivity.

\section{Urine analysis of interstitial cystitis/bladder pain syndrome patients}

Our group reported that IL-8 (CXCL-8) is elevated, along with other members of the CXC family of chemokines namely CXCL-1 and CXCL-10, in the urine of Hunner-type IC/BPS patients ${ }^{47}$. Erickson et al. found a positive association between elevated levels of CXCL- 8 in the urine and bladder mast cell counts of IC/BPS patients ${ }^{102}$. A subsequent study from her group reproduced the earlier reported elevation of CXCL-10 in Hunner-type IC/BPS patients ${ }^{39}$. Longitudinal analysis of the urine samples of IC/BPS patients at baseline and at follow-up further demonstrated the treatment-associated reduction in urinary chemokine levels following hydrodistension ${ }^{103}$ and sacral neuromodulation $^{104}$ at 4 and 24 weeks, respectively. A recent crowd-sourcing urine study confirmed the elevation of CXCL-1 and CXCL-8 in the urine of 153 IC/BPS patients ${ }^{105}$. Nerve growth factor $(\mathrm{NGF})^{106}$ is overexpressed in IC/BPS patients, and a recent meta-analysis of several studies found increased NGF levels in the urine of IC/BPS patients ${ }^{107}$. NGF overexpression in the bladder was linked to the deposition of type I collagen in the extracellular matrix of rat bladder ${ }^{108}$. TGF- $\beta 1$ is another signaling mediator shown to be responsible 
for fibrosis in rat bladder following exposure to ketamine ${ }^{109}$ or cyclophosphamide ${ }^{35}$.

\section{Potential applications of imaging tools in interstitial cystitis/bladder pain syndrome}

The identification of patients primarily afflicted with organic disease of the bladder wall ${ }^{7}$ and those with myofascial pain or disturbance in central pain processing can rationalize the clinical management of incipient IC/BPS. We envision that NCM-enhanced $\mathrm{T}_{1}$-weighted pelvic MRI can provide structural and functional imaging of the bladder wall to easily discriminate patients who have organic disease of the bladder wall from those who have pelvic floor hypertonicity. Only available current option of bladder wall biopsy for phenotyping IC/BPS patients with organic disease of the bladder wall, is invasive and riddled with potential complications, which makes it likely that such patients are under-represented in the numerous failed clinical trials on anti-inflammatory ${ }^{110,111}$ or GAG replacement ${ }^{112,113}$ therapies. Therefore, there is an unmet need for a non-invasive imaging method for assessing chronic inflammation in bladder wall of IC/BPS patients, which can enable the selection of IC/BPS patients most likely to respond to anti-inflammatory therapies. IC/BPS patients with organic disease of the bladder wall are expected to demonstrate higher bladder wall permeability for GBCAs, and such patients will be good candidates for GAG replacement therapy by pentosan polysulfate or other new intravesical treatments including liposomes, submucosal injection of steroids into the bladder wall ${ }^{114}$, or Vessilen ${ }^{\circledR}$ (a new formulation of $2 \%$ adelmidrol [the diethanolamide derivative of azelaic acid] $+0.1 \%$ sodium hyaluronate $)^{115}$. On the other hand, IC/BPS patients who do not exhibit bladder permeability changes on MRI are more likely to benefit from therapies directed at pelvic floor or central disturbances.

Fibrotic changes (collagen deposition) in the bladder wall are a well-known outcome of progressive IC/BPS ${ }^{15,33,34,45}$, ketamine abuse $^{41,116}$, and obstruction ${ }^{117,118}$. The inability to non-invasively measure fibrosis represents a major gap in the care and investigation of IC/BPS and other voiding disorders. Large volumetric data available from MRI can allow reconstruction of the bladder wall and pelvic structures ${ }^{101}$. Hunner's lesions and fibrotic changes in the bladder wall can be visualized using multiphase data sets acquired in a continuous fashion using novel free-breathing MRI sequence without predetermined temporal resolution, allowing for retrospective sparse reconstruction at flexible temporal resolution ${ }^{119}$. Increased permeability of the bladder wall can also be confirmed by the penetration and accumulation of 2-deoxy-2-[fluorine-18] fluoro-D-glucose in the bladder wall using positron emission tomography integrated with $\mathrm{CT}$ $\left({ }^{18} \mathrm{~F}-\mathrm{FDG}\right.$ PET/CT). PET with ${ }^{18} \mathrm{~F}-\mathrm{FDG}$, an analogue of glucose, provides valuable functional information based on the increased glucose uptake in the inflamed sites of the bladder wall before morphological alterations occur. The combined acquisition of PET and CT has synergistic advantages over PET or CT alone, as the combined approach minimizes individual limitations of each technique. Imaging tools have the potential to replace the subjective impressions of patients in objective quantification of symptoms and the clinical response of new drugs. The weak correlation between symptom questionnaire scores and patient satisfaction is considered a potential bottleneck in the continued scientific progress and new drug development for IC/BPS.

\section{Conclusions}

Recent advances in MRI of the bladder wall and brain can transform our understanding and care of patients with IC/BPS. High-resolution $\mathrm{T}_{1}$-weighted MRI and fMRI can inform on the disturbances in central processing of chronic pelvic pain. CE-MRI of the bladder wall has the potential to objectively separate three distinct entities of IC/BPS: pelvic hypersensitivity, IC/BPS, and IC/BPS with Hunner's lesions. Such objective classification can enable proper patient selection for drugs targeting chronic inflammation in the bladder wall and reduce the reliance on subjective outcomes for predicting the efficacy and safety of novel therapeutic interventions.

\section{Abbreviations}

BWT, bladder wall thickness; CE-MRI, contrast-enhanced magnetic resonance imaging; CNR, contrast-noise ratio; 2D, two dimensional; 3D, three dimensional; ESSIC, European Society for the Study of Interstitial Cystitis/bladder pain syndrome; FA, flip angle; FLASH, fast low angle shot; fMRI, functional magnetic resonance imaging; FOV, field of view; GAG, glycosaminoglycan; GBCA, gadolinium-based contrast agent; IC/BPS, interstitial cystitis/bladder pain syndrome; ICS, International Continence Society; MRI, magnetic resonance imaging; NGF, nerve growth factor; NIR, near infra-red; NIRS, near infra-red spectroscopy; PET, positron emission tomography; SNR, signal-to-noise ratio; SPIO, superparamagnetic iron oxide; T, Tesla; TE, echo time; TGF $\beta 1$, transforming growth factor $\beta 1$; TR, repetition time, UTI, urinary tract infection

\section{Grant information}

This work was partly supported by National Institute of Diabetes and Digestive and Kidney Diseases grant 1R41DK108397.

The funders had no role in study design, data collection and analysis, decision to publish, or preparation of the manuscript.

\section{Acknowledgements}

The authors would like to acknowledge the assistance of Janet Erickson and Anna Wecht, from University of Pittsburgh, in the clinical translation of novel contrast mixture. 
1. Wennevik GE, Meijlink JM, Hanno P, et al.: The Role of Glomerulations in Bladder Pain Syndrome: A Review. J Urol. 2016; 195(1): 19-25. PubMed Abstract | Publisher Full Text

2. Doggweiler R, Whitmore KE, Meijlink JM, et al.: A standard for terminology in chronic pelvic pain syndromes: A report from the chronic pelvic pain working group of the international continence society. Neurourol Urodyn. 2017; 36(4): 984-1008.

PubMed Abstract | Publisher Full Text

3. Mullins C, Bavendam T, Kirkali Z, et al:: Novel research approaches for interstitial cystitis/bladder pain syndrome: thinking beyond the bladder. Trans Androl Urol. 2015; 4(5): 524-33.

PubMed Abstract | Publisher Full Text | Free Full Text

4. Suskind AM, Berry SH, Ewing BA, et al:: The prevalence and overlap of interstitial cystitis/bladder pain syndrome and chronic prostatitis/chronic pelvic pain syndrome in men: results of the RAND Interstitial Cystitis Epidemiology male study. J Urol. 2013; 189(1): 141-5. PubMed Abstract | Publisher Full Text | Free Full Text

5. F Tung A, Hepp Z, Bansal A, et al.: Characterizing Health Care Utilization, Direct Costs, and Comorbidities Associated with Interstitial Cystitis: A Retrospective Claims Analysis. J Manag Care Spec Pharm. 2017; 23(4): 474-82. PubMed Abstract | Publisher Full Text | F1000 Recommendation

6. Hanno PM, Erickson D, Moldwin R, et al: Diagnosis and treatment of interstitial cystitis/bladder pain syndrome: AUA guideline amendment. J Urol. 2015; 193(5): 1545-53.

PubMed Abstract | Publisher Full Text

7. Walker SJ, Zambon J, Andersson KE, et al:: Bladder Capacity is a Biomarker for a Bladder Centric versus Systemic Manifestation in Interstitial Cystitis/Bladder Pain Syndrome. J Urol. 2017; 198(2): 369-75. PubMed Abstract | Publisher Full Text

8. Akiyama Y, Morikawa T, Maeda D, et al.: Increased CXCR3 Expression of Infiltrating Plasma Cells in Hunner Type Interstitial Cystitis. Sci Rep. 2016; 6 : 28652.

PubMed Abstract | Publisher Full Text | Free Full Text

9. Maeda D, Akiyama $Y$, Morikawa $T$, et al:: Hunner-Type (Classic) Interstitial Cystitis: A Distinct Inflammatory Disorder Characterized by Pancystitis, with Frequent Expansion of Clonal B-Cells and Epithelial Denudation. PLOS One. 2015; 10(11): e0143316.

PubMed Abstract | Publisher Full Text | Free Full Text

10. Ackerman AL, Lee UJ, Jellison FC, et al: MRI suggests increased tonicity of the levator ani in women with interstitial cystitis/bladder pain syndrome. Int Urogynecol J. 2016; 27(1): 77-83. PubMed Abstract | Publisher Full Text

11. Kairys AE, Schmidt-Wilcke T, Puiu T, et al.: Increased brain gray matter in the primary somatosensory cortex is associated with increased pain and mood disturbance in patients with interstitial cystitis/painful bladder syndrome. J Urol. 2015; 193(1): 131-7. PubMed Abstract | Publisher Full Text | Free Full Text

12. F Kilpatrick LA, Kutch JJ, Tillisch K, et al:: Alterations in resting state oscillations and connectivity in sensory and motor networks in women with interstitial cystitis/painful bladder syndrome. J Urol. 2014; 192(3): 947-55. PubMed Abstract | Publisher Full Text | Free Full Text | F1000 Recommendation

13. Lynes WL, Flynn SD, Shortliffe LD, et al:: The histology of interstitial cystitis. Am J Surg Pathol. 1990; 14(10): 969-76. PubMed Abstract | Publisher Full Tex

14. Logadottir $Y$, Delbro D, Fall M, et al.: Cytokine expression in patients with bladder pain syndrome/interstitial cystitis ESSIC type 3C. J Urol. 2014; 192(5): 1564-8.

PubMed Abstract | Publisher Full Text

15. Kastrup J, Hald T, Larsen S, et al:: Histamine content and mast cell count of detrusor muscle in patients with interstitial cystitis and other types of chronic cystitis. Br J Urol. 1983; 55(5): 495-500. PubMed Abstract | Publisher Full Text

16. Yoshimura N, Seki S, Chancellor MB, et al:: Targeting afferent hyperexcitability for therapy of the painful bladder syndrome. Urology. 2002; 59(5 Suppl 1):61-7. PubMed Abstract | Publisher Full Text

17. Pang $X$, Marchand J, Sant GR, et al:: Increased number of substance $\mathbf{P}$ positive nerve fibres in interstitial cystitis. Br J Urol. 1995; 75(6): 744-50. PubMed Abstract | Publisher Full Text

18. Erickson DR, Belchis DA, Dabbs DJ: Inflammatory cell types and clinical features of interstitial cystitis. J Urol. 1997; 158(3 Pt 1): 790-3. PubMed Abstract | Publisher Full Text

19. Esteban M, Adot JM, Arlandis S, et al:: Recommendations for the Diagnosis and Management of Bladder Pain Syndrome. Spanish Urological Association Consensus Document. Actas Urol Esp. 2015; 39(8): 465-72. PubMed Abstract | Publisher Full Text

20. Gamper M, Regauer S, Welter J, et al.: Are mast cells still good biomarkers for bladder pain syndrome/interstitial cystitis? J Urol. 2015; 193(6): 1994-2000. PubMed Abstract | Publisher Full Text

21. Theoharides TC, Kempuraj D Sant GR: Mast cell involvement in interstitial cystitis: a review of human and experimental evidence. Urology. 2001;

57(6 Suppl 1): $47-55$

PubMed Abstract | Publisher Full Text

22. Slobodov G, Feloney M, Gran C, et al.: Abnormal expression of molecular markers for bladder impermeability and differentiation in the urothelium of patients with interstitial cystitis. J Urol. 2004; 171(4): 1554-8.

PubMed Abstract | Publisher Full Text

23. Eldrup J, Thorup J, Nielsen SL, et al.: Permeability and ultrastructure of human bladder epithelium. Br J Urol. 1983; 55(5): 488-92.

PubMed Abstract | Publisher Full Text

24. Lilly JD, Parsons CL: Bladder surface glycosaminoglycans is a human epithelial permeability barrier. Surg Gynecol Obstet. 1990; 171(6): 493-6. PubMed Abstract

25. Parsons CL, Lilly JD, Stein P: Epithelial dysfunction in nonbacterial cystitis (interstitial cystitis). J Urol. 1991; 145(4): 732-5. PubMed Abstract | Publisher Full Text

26. Chelsky MJ, Rosen SI, Knight LC, et al:: Bladder permeability in interstitia cystitis is similar to that of normal volunteers: direct measurement by transvesical absorption of ${ }^{99 \mathrm{~m}}$ technetium-diethylenetriaminepentaacetic acid. J Urol. 1994; 151(2): 346-9. PubMed Abstract | Publisher Full Tex

27. Parsons $\mathrm{CL}$, Boychuk D, Jones $\mathrm{S}$, et al:: Bladder surface glycosaminoglycans: an epithelial permeability barrier. $J$ Urol $1990 ; 143(1): 139-42$ PubMed Abstract | Publisher Full Text

28. Liu HT, Shie JH, Chen SH, et al.: Differences in mast cell infiltration, E-cadherin, and zonula occludens- 1 expression between patients with overactive bladder and interstitial cystitis/bladder pain syndrome. Urology. 2012; 80(1): 225.e13-8. PubMed Abstract | Publisher Full Text

29. F Jhang JF, Ho HC, Jiang $\mathrm{YH}$, et al:: Electron microscopic characteristics of interstitial cystitis/bladder pain syndrome and their association with clinical condition. PLOS One. 2018; 13(6): e0198816. PubMed Abstract | Publisher Full Text | Free Full Text | F1000 Recommendation

30. Sun Y, Keay S, Lehrfeld TJ, et al.: Changes in adenosine triphosphatestimulated ATP release suggest association between cytokine and purinergic signaling in bladder urothelial cells. Urology. 2009; 74(5): 1163-8. PubMed Abstract | Publisher Full Text | Free Full Text

31. Dixon JS, Holm-Bentzen M, Gilpin CJ, et al:: Electron microscopic investigation of the bladder urothelium and glycocalyx in patients with interstitial cystitis. J Urol. 1986; 135(3): 621-5. PubMed Abstract | Publisher Full Tex

32. Theoharides TC, Sant GR, el-Mansoury M, et al: Activation of bladder mast cells in interstitial cystitis: a light and electron microscopic study. J Urol. 1995; 153(3 Pt 1): 629-36 PubMed Abstract | Publisher Full Text

33. F Kim A, Han JY, Ryu CM, et al:: Histopathological characteristics of interstitial cystitis/bladder pain syndrome without Hunner lesion. Histopathology. 2017; 71(3): 415-24.

PubMed Abstract | Publisher Full Text | F1000 Recommendation

34. Richter B, Roslind A, Hesse U, et al.: YKL-40 and mast cells are associated with detrusor fibrosis in patients diagnosed with bladder pain syndrome/interstitial cystitis according to the $\mathbf{2 0 0 8}$ criteria of the European Society for the Study of Interstitial Cystitis. Histopathology. 2010; 57(3): 371-83.

PubMed Abstract | Publisher Full Text

35. Tyagi P, Tyagi V, Yoshimura N, et al.: Gender-based reciprocal expression of transforming growth factor-beta1 and the inducible nitric oxide synthase in a rat model of cyclophosphamide-induced cystitis. J Inflamm (Lond). 2009; 6: 23. PubMed Abstract | Publisher Full Text | Free Full Text

36. F Ahn ST, Jeong HG, Park TY, et al.: Differences in Urodynamic Parameters According to the Presence of a Hunner Lesion in Women With Interstitial Cystitis/Bladder Pain Syndrome. Int Neurourol J. 2018; 22(Suppl 1): S55-61. PubMed Abstract | Publisher Full Text | Free Full Text | F1000 Recommendation

37. F Choi D, Han JY, Shin JH, et al.: Downregulation of WNT11 is associated with bladder tissue fibrosis in patients with interstitial cystitis/bladder pain syndrome without Hunner lesion. Sci Rep. 2018; 8(1): 9782. PubMed Abstract | Publisher Full Text | Free Full Text | F1000 Recommendation

38. F Doiron RC, Tolls V, Irvine-Bird K, et al:: Clinical Phenotyping Does Not Differentiate Hunner Lesion Subtype of Interstitial Cystitis/Bladder Pain Syndrome: A Relook at the Role of Cystoscopy. J Urol. 2016; 196(4): 1136-40. PubMed Abstract | Publisher Full Text | F1000 Recommendation

39. Hendrix L, Erickson D: Can Urine CXCL-1 And CXCL-10 Levels Serve As Noininvasive Markers For Hunner Lesions In Interstitial Cystitis/Bladder Pain Syndrome? Neurourol Urodyn. 2012; 31(2): 226. Reference Source

40. Lee JE, Yi BH, Lee HK, et al.: Correlation of cystoscopically confirmed periureterally located hunner lesion with vesicoureteral reflux: preliminary study in patients with interstitial cystitis. AJR Am J Roentgenol. 2015; 204(4): W457-60

PubMed Abstract | Publisher Full Text 
41. $\mathrm{F}$ Lin CC, Yang AH, Lin AT: Activation of the mTOR dependent signaling pathway underlies ketamine-induced uropathy. Neurourol Urodyn. 2017; 36(8): 1988-95.

PubMed Abstract | Publisher Full Text | F1000 Recommendation

42. Kim SH, Kim TB, Kim SW, et al:: Urodynamic findings of the painful bladder syndrome/interstitial cystitis: a comparison with idiopathic overactive bladder. J Urol. 2009; 181(6): 2550-4

PubMed Abstract | Publisher Full Text

43. Kirkemo A, Peabody M, Diokno AC, et al.: Associations among urodynamic findings and symptoms in women enrolled in the Interstitial Cystitis Data Base (ICDB) Study. Urology. 1997; 49(5A Suppl): 76-80. PubMed Abstract | Publisher Full Text

44. F Osborn DJ, Kaufman MR, Mock S, et al:: Urinary retention rates after intravesical onabotulinumtoxinA injection for idiopathic overactive bladder in clinical practice and predictors of this outcome. Neurourol Urodyn. 2015; 34(7): 675-8.

PubMed Abstract | Publisher Full Text | Free Full Text | F1000 Recommendation

45. SHIPTON EA: HUNNER'S ULCER (CHRONIC INTERSTITIAL CYSTITIS) A MANIFESTATION OF COLLAGEN DISEASE. Br J Urol. 1965; 37(4): 443-9. PubMed Abstract | Publisher Full Text

46. Oelke M, Khullar V, Wijkstra H: Review on ultrasound measurement of bladder or detrusor wall thickness in women: techniques, diagnostic utility, and use in clinical trials. World J Urol. 2013; 31(5): 1093-104. PubMed Abstract | Publisher Full Text

47. Tyagi $\mathrm{P}$, Killinger $\mathrm{K}$, Tyagi $\mathrm{V}$, et al:: Urinary chemokines as noninvasive predictors of ulcerative interstitial cystitis. J Urol. 2012; 187(6): 2243-8. PubMed Abstract | Publisher Full Text | Free Full Text

48. $\mathrm{F}$ Homma $\mathrm{Y}$, Ueda $\mathrm{T}$, Tomoe $\mathrm{H}$, et al: Clinical guidelines for interstitial cystitis and hypersensitive bladder updated in 2015. Int J Urol 2016; 23(7): 542-9. PubMed Abstract | Publisher Full Text | F1000 Recommendation

49. F Ueda T, Nakagawa M, Okamura M, et al:: New cystoscopic diagnosis for interstitial cystitis/painful bladder syndrome using narrow-band imaging system. Int J Urol. 2008; 15(12): 1039-43.

PubMed Abstract | Publisher Full Text | F1000 Recommendation

50. Khorasani B, Arab AM, Sedighi Gilani MA et al: Transabdominal ultrasound measurement of pelvic floor muscle mobility in men with and without chronic prostatitis/chronic pelvic pain syndrome. Urology. 2012; 80(3): 673-7. PubMed Abstract | Publisher Full Text

51. Milosević $\mathrm{D}$, Batinic $\mathrm{D}$, Vrljicak $\mathrm{K}$, et al:: Ultrasound distinction between simple recurrent urinary tract infections and a specific bladder wall inflammatory entity called cystitis cystica. Coll Antropol. 2014; 38(1): 151-4. PubMed Abstract

52. Rachaneni S, McCooty S, Middleton LJ, et al.: Bladder ultrasonography for diagnosing detrusor overactivity: test accuracy study and economic evaluation. Health Technol Assess. 2016; 20(7): 1-150. PubMed Abstract | Publisher Full Text | Free Full Text

53. Heritz DM, Thiessen JJ: Tiaprofenic acid: an uncommon cause of cystitis often misdiagnosed as interstitial cystitis. Can J Urol. 1996; 3(1): 202-5. PubMed Abstract

54. Weissleder R, Ntziachristos V: Shedding light onto live molecular targets. Nat Med. 2003; 9(1): 123-8.

PubMed Abstract | Publisher Full Tex

55. Yhee JY, Kim SA, Koo H, et al:: Optical imaging of cancer-related proteases using near-infrared fluorescence matrix metalloproteinase-sensitive and cathepsin B-sensitive probes. Theranostics. 2012; 2(2): 179-89. PubMed Abstract | Publisher Full Text | Free Full Text

56. Bremer C, Ntziachristos V, Weissleder R: Optical-based molecular imaging: contrast agents and potential medical applications. Eur Radiol. 2003; 13(2): 231-43.

PubMed Abstract

57. Nogawa M, Yuasa T, Kimura S, et al:: Intravesical administration of small interfering RNA targeting PLK-1 successfully prevents the growth of bladder cancer. J Clin Invest. 2005; 115(4): 978-85.

PubMed Abstract | Publisher Full Text | Free Full Text

58. Shadgan B, Nigro M, Macnab A, et al.: Optical diagnosis of lower urinary tract infection: a pilot study in children. J Pediatr Urol. 2015; 11(2): 74.e1-7. PubMed Abstract | Publisher Full Text

59. Kaneko G, Nishimoto $\mathrm{K}$, Ito $\mathrm{Y}$, et al:: The combination therapy of prednisolon and tacrolimus for severe painful bladder syndrome/interstitial cystitis. Can Urol Assoc J. 2012; 6(2): E46-9. PubMed Abstract | Free Full Text

60. F Rabie E, Faeghi F, Izadpanahi MH, et al:: Role of Dynamic ContrastEnhanced Magnetic Resonance Imaging in Staging of Bladder Cancer. J Clin Diagn Res. 2016; 10(4): TC01-5.

PubMed Abstract | Publisher Full Text | Free Full Text | F1000 Recommendation

61. Tyagi $\mathrm{P}$, Janicki J, Moon $\mathrm{CH}$, et al.: Novel contrast mixture achieves contrast resolution of human bladder wall suitable for T1 mapping: applications in interstitial cystitis and beyond. Int Urol Nephrol. 2018; 50(3): 401-9. PubMed Abstract | Publisher Full Text | Free Full Text

62. Fisher MR, Hricak H, Crooks LE: Urinary bladder MR imaging. Part I. Normal and benign conditions. Radiology. 1985; 157(2): 467-70. PubMed Abstract | Publisher Full Text
63. Ma Z, Jorge RN, Mascarenhas T, et al.: Novel approach to segment the inner and outer boundaries of the bladder wall in T2-weighted magnetic resonance images. Ann Biomed Eng. 2011; 39(8): 2287-97. PubMed Abstract | Publisher Full Text

64. Arum CJ, Kodama Y, Rolim N, et al.: A rat model of intravesical delivery of small interfering RNA for studying urinary carcinoma. World J Urol. 2010; 28(4): $479-85$.

PubMed Abstract | Publisher Full Text

65. Takeda K, Kawaguchi T, Shiraishi T, et al:: Normal bladder wall morphology in Gd-DTPA-enhanced clinical MR imaging using an endorectal surface coil and histological assessment of submucosal linear enhancement using $\left[{ }^{14} \mathrm{C}\right] \mathrm{Gd}-$ DOTA autoradiography in an animal model. Eur J Radiol. 1998; 26(3): 290-6. PubMed Abstract | Publisher Full Text

66. Verma S, Rajesh A, Prasad SR, et al.: Urinary bladder cancer: role of MR imaging. Radiographics. 2012; 32(2): 371-87.

PubMed Abstract | Publisher Full Text

67. Nguyen HT, Pohar KS, Jia G, et al:: Improving bladder cancer imaging using 3-T functional dynamic contrast-enhanced magnetic resonance imaging. Invest Radiol. 2014; 49(6): 390-5.

PubMed Abstract | Publisher Full Text | Free Full Text

68. Hakenberg OW, Linne C, Manseck A, et al:: Bladder wall thickness in normal adults and men with mild lower urinary tract symptoms and benign prostatic enlargement. Neurourol Urodyn. 2000; 19(5): 585-93.

PubMed Abstract | Publisher Full Text

69. Alsinnawi M, Torreggiani W, Sheikh M, et al.: Delayed contrast-enhanced MRI to localize Botox after cystoscopic intravesical injection. Int Urol Nephrol. 2015; 47(6): 893-8.

PubMed Abstract | Publisher Full Text

70. Roy C: Tumour pathology of the bladder: the role of MRI. Diagn Interv Imaging 2012; 93(4): 297-309.

PubMed Abstract | Publisher Full Text

71. Xiao D, Zhang G, Liu Y, et al:: 3D detection and extraction of bladder tumors via MR virtual cystoscopy. Int J Comput Assist Radiol Surg. 2016; 11(1): 89-97. PubMed Abstract | Publisher Full Text

72. Maeda $\mathrm{H}$, Kinukawa $\mathrm{T}$, Hattori $\mathrm{R}$, et al.: Detection of muscle layer invasion with submillimeter pixel MR images: staging of bladder carcinoma. Magn Reson Imaging. 1995; 13(1): 9-19.

PubMed Abstract | Publisher Full Text

73. Kim B, Semelka RC, Ascher SM, et al.: Bladder tumor staging: comparison of contrast-enhanced CT, T1- and T2-weighted MR imaging, dynamic gadoliniumenhanced imaging, and late gadolinium-enhanced imaging. Radiology. 1994; 193(1): 239-45

PubMed Abstract | Publisher Full Text

74. Krhut J, Samal V, Nemec D, et al: Intradetrusor versus suburothelial onabotulinumtoxinA injections for neurogenic detrusor overactivity: a pilot study. Spinal Cord. 2012; 50(12): 904-7. PubMed Abstract | Publisher Full Text

75. Narumi $\mathrm{Y}$, Kadota $\mathrm{T}$, Inoue $\mathrm{E}$, et al.: Bladder wall morphology: in vitro MR imaging-histopathologic correlation. Radiology. 1993; 187(1): 151-5. PubMed Abstract | Publisher Full Text

76. Teufl F, Dammann F, Wehrmann M: [In vitro study of morphology of the bladder wall using MR tomography at 1.0 Tesla: correlation with histology]. Rofo. 1997; 166(5): 406-10.

PubMed Abstract | Publisher Full Text

77. Babcock EE, Brateman L, Weinreb JC, et al:: Edge artifacts in MR images: chemical shift effect. $J$ Comput Assist Tomogr. 1985; 9(2): 252-7. PubMed Abstract

78. Hood MN, Ho VB, Smirniotopoulos JG, et al: Chemical shift: the artifact and clinical tool revisited. Radiographics. 1999; 19(2): 357-71. PubMed Abstract | Publisher Full Text

79. Lin Q, Liang Z, Duan C, et al:: Motion correction for MR cystography by an image processing approach. IEEE Trans Biomed Eng. 2013; 60(9): 2401-10. PubMed Abstract | Publisher Full Text | Free Full Text

80. Elster AD, Sobol WT, Hinson WH: Pseudolayering of Gd-DTPA in the urinary bladder. Radiology. 1990; 174(2): 379-81.

PubMed Abstract | Publisher Full Text

81. Rohrer M, Bauer H, Mintorovitch J, et al.: Comparison of magnetic properties of MRI contrast media solutions at different magnetic field strengths. Invest Radiol. 2005; 40(11): 715-24.

PubMed Abstract | Publisher Full Text

82. Scattoni V, Da Pozzo LF, Colombo R, et al.: Dynamic gadolinium-enhanced magnetic resonance imaging in staging of superficial bladder cancer. $J$ Urol. 1996; 155(5): 1594-9.

PubMed Abstract | Publisher Full Text

83. Carr DH, Brown J, Bydder GM, et al:: Gadolinium-DTPA as a contrast agent in MRI: initial clinical experience in 20 patients. AJR Am J Roentgenol. 1984; 143(2): 215-24

PubMed Abstract | Publisher Full Text

84. Sparenberg A, Hamm B, Hammerer P, et al.: [The diagnosis of bladder carcinomas by NMR tomography: an improvement with Gd-DTPA?]. Rofo. 1991; 155(2): 117-22.

PubMed Abstract | Publisher Full Text

85. Lee SK, Chang Y, Park NH, et al.: Magnetic resonance voiding cystography 
in the diagnosis of vesicoureteral reflux: comparative study with voiding cystourethrography. J Magn Reson Imaging. 2005; 21(4): 406-14. PubMed Abstract | Publisher Full Text

86. F Towner RA, Wisniewski AB, Wu DH, et al:: A Feasibility Study to Determine Whether Clinical Contrast Enhanced Magnetic Resonance Imaging can Detect Increased Bladder Permeability in Patients with Interstitial Cystitis. J Urol. 2016; 195(3): 631-8.

PubMed Abstract | Publisher Full Text | Free Full Text | F1000 Recommendation

87. Beyersdorff $\mathrm{D}$, Taupitz $\mathrm{M}$, Giessing $\mathrm{M}$, et al:: [The staging of bladder tumors in MRT: the value of the intravesical application of an iron oxide-containing contrast medium in combination with high-resolution $\mathrm{T}_{2}$-weighted imaging] Rofo. 2000; 172(6): 504-8.

PubMed Abstract | Publisher Full Text

88. Tyagi $\mathrm{P}$, Janicki JJ, Hitchens TK, et al:: Novel contrast mixture improves bladder wall contrast for visualizing bladder injury. Am J Physiol Renal Physiol. 2017; 313(2): F155-F162

PubMed Abstract | Publisher Full Text | Free Full Text

89. Colaco M, Koslov DS, Keys T, et al.: Correlation of gene expression with bladder capacity in interstitial cystitis/bladder pain syndrome. J Urol. 2014; 192(4): $1123-9$

PubMed Abstract | Publisher Full Text

90. Nirmal J, Tyagi $\mathrm{P}$, Chancellor MB, et al:: Development of potential orphan drug therapy of intravesical liposomal tacrolimus for hemorrhagic cystitis due to increased local drug exposure. J Urol. 2013; 189(4): 1553-8.

PubMed Abstract | Publisher Full Text

91. Towner RA, Smith N, Saunders D, et al:: Contrast enhanced magnetic resonance imaging as a diagnostic tool to assess bladder permeability and associated colon cross talk: preclinical studies in a rat model. J Urol. 2015; 193(4): 1394-400. PubMed Abstract | Publisher Full Text | Free Full Text

92. Chuang YC, Huang TL, Tyagi $P$, et al:: Urodynamic and Immunohistochemical Evaluation of Intravesical Botulinum Toxin A Delivery Using Low Energy Shock Waves. J Urol. 2016; 196(2): 599-608. PubMed Abstract | Publisher Full Text

93. Bloch F: The Principle of Nuclear Induction. Science. 1953; 118(3068): 425-30. PubMed Abstract | Publisher Full Text

94. Gowland $\mathrm{P}$, Mansfield $\mathrm{P}$, Bullock $\mathrm{P}$, et al:: Dynamic studies of gadolinium uptake in brain tumors using inversion-recovery echo-planar imaging. Magn Reson Med. 1992; 26(2): 241-58.

PubMed Abstract | Publisher Full Text

95. Deoni SC: Quantitative relaxometry of the brain. Top Magn Reson Imaging. 2010; 21(2): 101-13.

PubMed Abstract | Publisher Full Text | Free Full Text

96. Fu Y, Tanaka K, Nishimura S: Evaluation of brain edema using magnetic resonance proton relaxation times. Adv Neurol. 1990; 52: 165-76. PubMed Abstract

97. Béné GJ: Water proton relaxation times: main parameters in nuclear magnetic resonance medical diagnosis. Prog Nucl Med. 1984; 8: 1-14. PubMed Abstract

98. Stadler A, Jakob PM, Griswold M, et al: $\boldsymbol{T}_{1}$ mapping of the entire lung parenchyma: Influence of respiratory phase and correlation to lung function test results in patients with diffuse lung disease. Magn Reson Med. 2008; 59(1): 96-101.

PubMed Abstract | Publisher Full Text

99. Constantinou CE, Hvistendahl G, Ryhammer A, et al:: Determining the displacement of the pelvic floor and pelvic organs during voluntary contractions using magnetic resonance imaging in younger and older women. BJU Int. 2002; 90(4): 408-14. PubMed Abstract | Publisher Full Text

100. Ebert AK, Rösch WH, Vogt T: Safety and tolerability of adjuvant topical tacrolimus treatment in boys with lichen sclerosus: a prospective phase 2 study. Eur Urol. 2008; 54(4): 932-7. PubMed Abstract | Publisher Full Text

101. Tang ST, Cao GQ, Mao YZ, et al:: Clinical value of pelvic 3-dimensional magnetic resonance image reconstruction in anorectal malformations. J Pediatr Surg. 2009; 44(12): 2369-74.

PubMed Abstract | Publisher Full Text

102. Erickson DR, Tomaszewski JE, Kunselman AR, et al.: Urine markers do not predict biopsy findings or presence of bladder ulcers in interstitial cystitis/ painful bladder syndrome. J Urol. 2008; 179(5): 1850-6. PubMed Abstract | Publisher Full Text | Free Full Text

103. Corcoran AT, Yoshimura N, Tyagi V, et al:: Mapping the cytokine profile of painful bladder syndrome/interstitial cystitis in human bladder and urine specimens. World J Urol. 2013; 31(1): 241-6.

PubMed Abstract | Publisher Full Text | Free Full Text

104. Peters KM, Jayabalan N, Bui D, et al.: Effect of Sacral Neuromodulation on Outcome Measures and Urine Chemokines in Interstitial Cystitis/Painful Bladder Syndrome Patients. Low Urin Tract Symptoms. 2015; 7(2): 77-83. PubMed Abstract | Publisher Full Text

105. Lamb LE, Janicki JJ, Bartolone SN, et al.: Development of an interstitial cystitis risk score for bladder permeability. PLoS One. 2017; 12(10): e0185686. PubMed Abstract | Publisher Full Text | Free Full Text

106. Lowe EM, Anand P, Terenghi G, et al.: Increased nerve growth factor levels in the urinary bladder of women with idiopathic sensory urgency and interstitia cystitis. Br J Urol. 1997; 79(4): 572-7. PubMed Abstract | Publisher Full Tex

107. F Chen W, Ye DY, Han DJ, et al.: Elevated level of nerve growth factor in the bladder pain syndrome/interstitial cystitis: a meta-analysis. Springerplus. 2016; 5(1): 1072.

PubMed Abstract | Publisher Full Text | Free Full Text | F1000 Recommendation

108. Chung CW, Zhang QL, Qiao LY: Endogenous nerve growth factor regulates collagen expression and bladder hypertrophy through Akt and MAPK pathways during cystitis. J Biol Chem. 2010; 285(6): 4206-12. PubMed Abstract | Publisher Full Text | Free Full Text

109. F Wang J, Chen Y, Di Gu, et al:: Ketamine-induced bladder fibrosis involves epithelial-to-mesenchymal transition mediated by transforming growth factorB1. Am J Physiol Renal Physiol. 2017; 313(4): F961-F972. PubMed Abstract | Publisher Full Text | F1000 Recommendation

110. F Bosch PC: A randomized, double-blind, placebo controlled trial of adalimumab for interstitial cystitis/bladder pain syndrome. J Urol. 2014; 191(1): $77-82$.

PubMed Abstract | Publisher Full Text | F1000 Recommendation

111. F Nickel JC, Crossland A, Davis E, et al:: Investigation of a $\mathrm{Ca}^{2+}$ channel $\boldsymbol{\alpha 2 \delta}$ ligand for the treatment of interstitial cystitis: results of a randomized, doubleblind, placebo controlled phase II trial. J Urol. 2012; 188(3): 817-23. PubMed Abstract | Publisher Full Text | F1000 Recommendation

112. Nickel JC, Herschorn S, Whitmore KE, et al.: Pentosan polysulfate sodium for treatment of interstitial cystitis/bladder pain syndrome: insights from a randomized, double-blind, placebo controlled study. J Urol. 2015; 193(3): 857-62.

PubMed Abstract | Publisher Full Text

113. Nickel JC, Hanno P, Kumar K, et al:: Second multicenter, randomized, doubleblind, parallel-group evaluation of effectiveness and safety of intravesical sodium chondroitin sulfate compared with inactive vehicle control in subjects with interstitial cystitis/bladder pain syndrome. Urology. 2012; 79(6): 1220-4. PubMed Abstract | Publisher Full Text

114. F Funaro MG, King AN, Stern JNH, et al.: Endoscopic Injection of Low Dose Triamcinolone: A Simple, Minimally Invasive, and Effective Therapy for Interstitial Cystitis With Hunner Lesions. Urology. 2018; 118: 25-9. PubMed Abstract | Publisher Full Text | F1000 Recommendation

115. F Ostardo E, Impellizzeri D, Cervigni M, et al.: Adelmidrol + sodium hyaluronate in IC/BPS or conditions associated to chronic urothelial inflammation. A translational study. Pharmacol Res. 2018; 134: 16-30. PubMed Abstract | Publisher Full Text | F1000 Recommendation

116. Lin HC, Lee HS, Chiueh TS, et al.: Histopathological assessment of inflammation and expression of inflammatory markers in patients with ketamine-induced cystitis. Mol Med Rep. 2015; 11(4): 2421-8. PubMed Abstract | Publisher Full Text | Free Full Text

117. Metcalfe $\mathrm{PD}$, Wang $\mathrm{J}$, Jiao $\mathrm{H}$, et al:: Bladder outlet obstruction: progression from inflammation to fibrosis. BJU Int. 2010; 106(11): 1686-94. PubMed Abstract | Publisher Full Text

118. Klarskov $\mathrm{P}$, Holm-Bentzen M, Larsen S, et al:: Partial cystectomy for the myogenic decompensated bladder with excessive residual urine. Urodynamics, histology and 2-13 years follow-up. Scand J Urol Nephrol. 1988; 22(4): 251-6. PubMed Abstract | Publisher Full Text

119. F Parikh N, Ream JM, Zhang HC, et al:: Performance of simultaneous high temporal resolution quantitative perfusion imaging of bladder tumors and conventional multi-phase urography using a novel free-breathing continuously acquired radial compressed-sensing MRI sequence. Magn Reson Imaging. 2016; 34(5): 694-8.

PubMed Abstract | Publisher Full Text | Free Full Text | F1000 Recommendation 


\section{Open Peer Review}

\section{Current Peer Review Status:}

\section{Editorial Note on the Review Process}

Faculty Reviews are review articles written by the prestigious Members of Faculty Opinions. The articles are commissioned and peer reviewed before publication to ensure that the final, published version is comprehensive and accessible. The reviewers who approved the final version are listed with their names and affiliations.

\section{The reviewers who approved this article are:}

\section{Version 1}

\section{Myung-Soo Choo}

Department of Urology, University of Ulsan College of Medicine, Seoul, South Korea

Competing Interests: No competing interests were disclosed.

\section{Longkun Li}

Department of Urology, Second Affiliated Hospital, Third Military Medical University, Chongqing, China Competing Interests: No competing interests were disclosed.

The benefits of publishing with F1000Research:

- Your article is published within days, with no editorial bias

- You can publish traditional articles, null/negative results, case reports, data notes and more

- The peer review process is transparent and collaborative

- Your article is indexed in PubMed after passing peer review

- Dedicated customer support at every stage

For pre-submission enquiries, contact research@f1000.com 